2-carbon, the relative contributions of the glucose carbons to the carbon dioxide production can be calculated as (per cent) : $\mathrm{C}_{1}, 9.2 ; \mathrm{C}_{2}, 5.7 ; \mathrm{C}_{8}$ and $\mathrm{C}_{4}$ together, $74 \cdot 2 ; \mathrm{C}_{5}, 5 \cdot 7 ; \mathrm{C}_{6}, 5 \cdot 2$. Nevertheless, all the glucose carbons contribute to the carbon dioxide production and the 1-carbon contributes more than the 6-carbon. Consequently, reactions other than the Embden-Meyerhof-Parnas glycolysis ones must be involved to some extent.

The labelling of the carboxyl group of lactic acid is noteworthy. It is probably a result of carbon dioxide fixation, which is known to occur during glucose fermentation by Chlorella ${ }^{1}$.

Department of Botany,

University College, Gower Street,

London, W.C.1. Oct. 10.

${ }^{1}$ Wong, H. A., and Syrett, P. J. (in the press).

${ }^{2}$ Bulen, W. A., Varner, J. E., and Burrell, R. C., Anal. Chem., 24, 187 (1952).

${ }^{8} \mathrm{Katz}$, J., Abraham, S., and Chaikoff, I. L., Anal. Chem., 27, 155 (1955).

\section{Isolation of Oxo-Steroids under Neutral Conditions}

GIRARD's reagent $T$ (trimethylammonium hydrazide chloride $)^{1}$ is extensively used for the separation of oxo-steroids from other steroids and particularly for purification of 17-oxo-steroids in extracts of acid-or enzyme-hydrolysed urine ${ }^{2}$. The method employed usually involves dissolving the material and Girard reagent in glacial acetic acid, and either heating the mixture for periods of up to $1 \mathrm{hr}$. or allowing it to stand overnight at room temperature. During this procedure destruction of labile steroids and some acetylation of hydroxy-steroids tend to occur (ref. 3 and unpublished observations).

Before extraction of non-ketonic material from the water-soluble Girard complex the acetic acid is nine-tenths neutralized by addition of strong alkali. The heat evolved, which may be deleterious to some steroids, is counteracted by carrying out the neutralization under ice-cold conditions. After extraction of the non-ketonic material the Girard complex is hydrolysed by taking the solution to $p \mathrm{H} 1$ and allowing it to stand for 2-48 hr. Under these conditions destruction of labile steroids may occur.

Recently, Teitelbaum ${ }^{4}$ has described an elegant modification of the method for application to labile aldehydes and ketones such as citral, benzaldehyde, etc., which are extensively destroyed by the old method. The new method involves forming the Girard complex in ethanolic solution in the presence of cation exchange resin ('Amberlite $I R C 50$ '), and then splitting the complex by adding excess aqueous formaldehyde. Thus many of the disadvantages of the old method have been avoided, and also the new method is simpler and less time-consuming.

The applicability of the new method to oxosteroids has therefore been investigated. In these exploratory experiments the steroids used were progesterone (I) and 21-hydroxy-5 $\beta$-pregnane-3 : 20 dione (II) (pregnanediolone). The steroid (10 mgm.) was dissolved in $1 \mathrm{ml}$. ethanol and $20 \mathrm{mgm}$. Girard reagent $T$ and $5 \mathrm{mgm}$. 'Amberlite IRC50' were added. The mixture was heated under reflux for $1 \mathrm{hr}$., and after addition of $10 \mathrm{ml}$. water was extracted $3 \times$ with $10 \mathrm{ml}$. solvent (ether for I ethyl acetate for II). The amount of steroid appearing in this non-ketonic fraction was then determined. After addition of
$2 \mathrm{ml}$. of 40 per cent formalin, the aqueous solution of the Girard complex was allowed to stand overnight. Extraction with solvent then yielded the ketonic fraction. For comparison $10 \mathrm{mgm}$. steroid were also treated by the old method ${ }^{2}$.

The results presented in Table 1 show that the new method is more effective than the old.

\begin{tabular}{|c|c|}
\hline Steroid & $\begin{array}{l}\text { Percentage recovery from : } \\
\begin{array}{ll}\text { (a) Non-ketonic (b) Ketonic } \\
\text { fraction } & \text { fraction }\end{array}\end{array}$ \\
\hline $\begin{array}{l}\text { Old method } \\
\text { New method }\end{array}$ & $\begin{array}{l}0 \cdot 5-1 \cdot 5 \\
0 \cdot 4-1 \cdot 0\end{array}$ \\
\hline $\begin{array}{l}\text {-Hyaroxy-op-pregnane-3:2 } \\
\text { Old method } \\
\text { New method } \\
\text { * Approximately } 10 \text { per ce }\end{array}$ & $\begin{array}{ll}<1 & 80-82 * \\
<1 & 90-95 \\
\text { ras acetylated } & 9 t \quad C-21\end{array}$ \\
\hline
\end{tabular}

Further experiments were carried out with progesterone to determine the rate of formation of the Girard complex at room-temperature using the new method. The results are shown in Table 2 . It can be seen that complex formation is fairly rapid at room temperature, and is virtually complete in $7 \mathrm{hr}$.

$\begin{array}{lccccccc} & \text { Table } 2 & & & & & \\ \text { Time (hr.) } & 0.25 & 0.5 & 1 & 2 & 3 & 7 & 24 \\ \begin{array}{c}\text { Progesterone in non-ketonic fraction } \\ \text { (per cent) }\end{array} & 84 & 76 & 55 & 15 & 10 & 3 & 1\end{array}$

The rate of splitting of the Girard reagentprogesterone complex by formaldehyde was also investigated, and the results are shown in Table 3.

$\begin{array}{lcccccc}\text { Time (hr.) } & \text { Table 3 } & & & & & \\ \text { Progesterone in ketonic fraction (per cent) } & 40 & 7 & 7 & 17 & 24 \\ & 40 & 95 & 98 & 98\end{array}$

Thus it is apparent that this new method of using the Girard reagent is applicable to steroids, and in view of the mild conditions employed it is recommended for use, particularly in work with labile steroids.

I wish to acknowledge gifts of steroids from Drs. C. L. Hewett (Organon) and G. D. Laubach (Pfizer).

Physiology Department, W. TAYLOR Medical School, King's College, Newcastle upon Tyne 1.

1 Girard, A., and Sandulesco, G., Helv. Chim Acta, 19, 1095 (1936). 'Pincus, G., and Pearlman, W. H., Endocrinol., 29, 413 (1941). ${ }^{3}$ Brooks, R. V., Biochem. J., 68, 50 (1958)

- Teitelbaum, C. L., J. Org. Chem., 28, 646 (1958).

\section{Electroencephalograph Correlates of Ammonium Carbonate Intoxication in the Rat}

IN the literature ${ }^{1,2}$ relating to ammonia intoxication in man and animals, the basic assumption has been that ammonia exerts a primary chemical action on brain cells. However, of the two papers in the animal experimental group on the effect of ammonia on the functioning of the central nervous system using electroencephalography, Marsan et al. ${ }^{3}$ interpreted the transiently decreased electrical activity observed in the dog's brain as a direct consequence of general cellular anoxia due to an embarrassed cardiac output ; and Torda ${ }^{4}$ believed her results indicated an increase in cerebral activity because of the paroxysmal slow waves following the intraperitoneal injection of ammonium chloride. We have demonstrated that under proper conditions of administration of ammonium salt, a primary cortical neuronal response may be achieved, as evidenced by a decreased electric output. 